\title{
O processo autopoiético e a construção de aprendizagens de acadêmicos do curso de Pedagogia a distância da UFRGS a partir do portfólio de aprendizagens
}

\author{
Mauro Lorençatto, IFSC \\ maurolorencatto@yahoo.com.br
}

\begin{abstract}
Resumo. Este artigo busca compreender a complexidade da construção de aprendizagens de acadêmicos do curso de licenciatura em Pedagogia, modalidade de educação a distância, da Universidade Federal do Rio Grande do Sul (PEAD/UFRGS) a partir das autonarrativas dos portfólios de aprendizagens. Tem como objetivo geral identificar as perturbações e reconhecer as compensações autopoiéticas ao longo do percurso de aprendizagens de dois estudantes que representam dois perfis acadêmicos. A opção metodológica é a pesquisa qualitativa de abordagem fenomenológica e a investigação utiliza como fonte de dados as autonarrativas dos portfólios de aprendizagens dos acadêmicos. Ao final do estudo, apresentam-se as ilustrações das plasticidades dos percursos autopoiéticos pelos quais se pode concluir que quanto mais crítico-construtivas são as intervenções dos tutores de sede no processo de aprendizagens, mais frequentes é a geração de perturbações e a realização de compensações que alteram a estrutura cognitiva dos acadêmicos.
\end{abstract}

Palavras-chave: processo autopoiético, autonarrativas de aprendizagens, educação a distância, PEAD.

\section{The autopoietic process and the construction of learning of students of Pedagogy UFRGS distance from the portfolio of learning}

\begin{abstract}
This file seeks to understand the complexity of learning construction of the Pedagogy graduation course, mode of distance education, of the Universidade Federal do Rio Grande do Sul (PEAD/UFRGS) starting from learning self-narration portfolios. Its general goal is to identify the distresses and to recognize the compensation of disturbances autopoietic along in the self-narration trajectories of learning two students representing two academic profiles. The methodology makes use of a phenomenological qualitative approach. The research uses as its source of data collection, the self-narration portfolio of academics learning. At the end of the study, it is presented the illustrations of autopoietic plasticity pathways by which it can be concluded that the more critical and constructive are the interventions of the tutors of headquarters in the process of learning, the most frequent is the generation of disturbances and implementation of compensation that alter the structure of the cognitive academics.
\end{abstract}

Keywords: autopoietic process, learning self-narrations, distance education, PEAD. 


\section{Introdução}

O desenvolvimento de novas Tecnologias Digitais, no decorrer da década de 2000, conduziu à difusão das oportunidades concerne à aprendizagem no Brasil através da combinação de recursos tecnológicos e do capital humano. A sua presença crescente no sistema educacional leva a refletir sobre pontos intrínsecos à educação, como: didática, metodologia, plataformas digitais, ferramentas online de avaliação.

Os estudos sobre a Educação a Distância (EAD), em que o acadêmico não tem contato físico com professores e colegas ou tem pouco contato, têm crescido, pois a utilização das tecnologias digitais permitiu alargar o alcance e as possibilidades da EAD. A utilização de ferramentas online para autoavaliação da aprendizagem têm evoluído ao longo dos últimos anos, devido à aplicação de concepções pedagógicas com ênfase na avaliação participativa através das autonarrativas do processo de aprendizagem dos estudantes.

O foco deste estudo é analisar as autonarrativas de aprendizagem realizadas através da ferramenta online de avaliação denominada Portfólio de Aprendizagens, de dois acadêmicos do curso de Pedagogia a Distância da UFRGS (PEAD). Cada acadêmico representa um dos dois perfis identificados na pré-seleção de dez acadêmicos num dos cinco polos do curso. O perfil do acadêmico ZS configura-se por menor regularidade de autonarrativas, esporádicas intervenções dos tutores de sede e autonarrativas incompletas ${ }^{1}$. Já o perfil do acadêmico PM configura-se por maior regularidade de autonarrativas, frequentes intervenções dos tutores de sede $\mathrm{e}$ autonarrativas completas.

Amplia-se a análise ao pensar sobre o conceito de autopoiese de Humberto Maturana e Francisco Varela proposto no início da década de 1970. A intenção é pensar a complexa conexão entre perturbação e compensação no processo de construção de aprendizagens a partir das autonarrativas dos portfólios. O componente do processo autopoiético em foco é a plasticidade das conexões entre perturbação e compensação. $O$ questionamento se direciona para a análise do processo de aprendizagem a partir da interação entre os acadêmicos e os tutores de sede pela ferramenta online de avaliação: portfólio de aprendizagens.

\section{O conceito de autopoiese}

Desde o século XV até o século XIX o paradigma predominante na construção de ciência foi o paradigma cartesiano, pelo qual o conhecimento se dá numa relação estável do sujeito com o objeto. O paradigma cartesiano considera, por um lado, a realidade de forma linear, fragmentada como se fosse uma coleção de coisas e, por outro lado, estável onde o sujeito que estuda essas questões é sempre externo a elas, não influenciando nas suas concepções. Dessa forma, a realidade é a simples representação de coisas e estados externos ao ser humano.

Contudo, a evolução da humanidade proporcionou o surgimento de objetos não simples, isto é, objetos que não se explicam pelos critérios lineares e representacionistas do paradigma cartesiano. Inclusive, com o intuito de evidenciar a escolha da aplicação do conceito de autopoiese, neste estudo, para além do construtivismo, é pertinente esclarecer alguns pontos centrais que demonstram a elevação epistêmica das teorias holísticas (autopoiese), em relação às teorias construtivistas. Para tanto, utiliza-se das palavras de Oliveira para esclarecer essa questão. 
[...] chamamos a atenção para algumas diferenças existentes entre essas duas posturas epistêmicas (holismo e construtivismo): o construtivismo alicerça-se na existência de estruturas, o holismo raramente as admite. No holismo epistemológico: a) o todo é maior do que a soma das partes; b) existe uma interação a simultâneo sujeito-nicho, o que coloca o holismo fora da dicotomia sujeito-objeto; o construtivismo aceita essa dicotomia, articulandoa dialeticamente e por etapas (OLIVEIRA, 1999, p.348).

Além disso, segundo Pellanda (2009), na postura epistêmica do construtivismo piagetiano, percebe-se elementos destoantes da postura epistêmica holística da autopoiese, tais como: a) uma forte dicotomia sujeito/objeto, b) a previsão de etapas de desenvolvimentos previsíveis (pensamento lógico-formal), c) uma dependência de captação externa para a construção da realidade (assimilação) e d) a busca de estabilizações durante o processo de produção de conhecimento.

O construtivismo teve importância para a ciência, contudo, a evolução epistêmica acende uma luz no caminho da ciência que permite enxergar a realidade não mais como uma relação direta e obrigatória, definida a priori, ou seja, antes da experimentação, mas sim, como uma relação indireta e contingente, configurada $a$ posteriori como é o caso da autopoiese.

Na eminência dessa mudança paradigmática surge a teoria da Biologia da Cognição, elaborada por Humberto Maturana e Francisco Varela (década de 1970), cujo conceito fundante é a autopoiese. Essa teoria afirma que os seres humanos são organizações que se estruturam na dinâmica da própria existência que se estabelece pelas relações internas com o meio de convivência. Essas relações são denominadas “domínios existenciais”. No fluxo cotidiano, nos domínios existenciais, os seres humanos interagem com outros humanos e com o próprio meio. Essa interação é chamada de "acoplamento estrutural". Entretanto, o acoplamento estrutural não tem caráter definidor na estruturação do ser humano, pois, assim como as relações se desenvolvem pelo acoplamento estrutural, a conservação e as alterações na estrutura cognitiva, isto é, no potencial de aprendizagem, se desenvolvem pela "clausura operacional” do sistema humano. Maturana e Varela (1997, p. 71), fundamentam esta dinâmica da gestão da própria existência através do conceito autopoiese entendido como a capacidade de "especificar e produzir continuamente sua própria organização através da produção de seus componentes”.

$\mathrm{Na}$ existência autopoiética dos humanos a linguagem é o elemento que permite as interações entre esses seres biologicamente sociais e socialmente biológicos. Para Maturana (2001a, p. 130), “a linguagem acontece quando duas ou mais pessoas operam através de suas interações recorrentes numa rede de coordenações cruzadas, recursivas, consensuais de coordenações consensuais de ações”. O ser humano existe como observador do outro e de si pela linguagem. De acordo com Maturana (2001a), a convivência dos seres humanos pela linguagem é denominada de conversação e a narração é um tipo de discurso que permite tal conversação pela sua sequencialidade e pela sua novidade.

A narrativa apresenta-se como uma série de elementos mediatos e imediatos, fortemente imbricados; a distaxia orienta uma leitura "horizontal", mas a integração superpõe-lhe uma leitura "vertical”: há uma espécie de "encaixamento" estrutural, como um jogo incessante de potenciais [...] pelo curso destes dois caminhos, a estrutura ramifica-se, prolifera-se, descobre-se: o novo não cessa de ser regular (Barthes, 1971 apud Santaella, 2005, p. 322). 
Santaella (2005, p. 289), corrobora com Maturana ao afirmar que "os textos narrativos são aqueles que organizam ações e eventos em uma ordem sequencial”. Tudo o que o ser humano é, o é, pela e na linguagem, ou seja, o viver-conhecer dos seres humanos, como seres autopoiéticos, se edifica na linguagem pela ação de linguagear. Sendo assim, ainda conforme a autora (2005) a autonarrativa é a narração do próprio universo de ação, do fazer: ação que é narrada. Portanto, a autonarrativa se caracteriza como o registro linguístico de eventos ou situações. Mas só há ação onde existe conflito, isto é, ação que gera reação e dessa interação nasce o acontecimento, o fato, o fenômeno.

\section{O ser humano é um ser fenomenologicamente autopoiético}

A organização da estrutura cognitiva de um ser humano se define e se configura pelo processo autopoiético de viver-conhecer. O processo de modificação estrutural cognitiva do ser humano, o qual constitui sua fenomenologia, é consequente do percurso autopoiético vivenciado.

Percebe-se que o conceito autopoiese potencializa os processos de interação entre os seres humanos pela sistemática de perturbações e compensações. O percurso autopoiético dos seres humanos (unidades autopoiéticas) se desenvolve num domínio fenomenológico específico e a partir das interações ocorrem transformações nas estruturas das unidades.

Cada domínio existencial fenomenológico tem sua sistemática de relações que se pode explicar apenas no contexto de cada domínio ${ }^{2}$. Nesses domínios existenciais as interações dos seres humanos com o meio causam inquietações que são absorvidas e transformadas em parte integrante do próprio ser a partir do processo autopoiético de compensação de perturbação ${ }^{3}$.

O domínio de um ser autopoiético no qual se realizam as compensações das perturbações é o domínio cognoscitivo. De acordo com Maturana e Varela (1997, p. 116), "toda conduta é expressão de conhecimento e todo conhecimento é conduta descritiva". Por isso, para eles, viver e conhecer são inseparáveis: "Viver é conhecer e conhecer é viver”. O desenvolvimento existencial de um ser autopoiético, em especial, do ser humano verifica-se pelas suas condutas em cada momento da sua vida.

A conduta sempre surge de uma fenomenologia que acontece no presente. No entanto, como objetos de nossa auto-observação ou como observadores da conduta de outros seres, vemos que as experiências passadas de um organismo modificam seu sistema nervoso, e parecem atuar como agentes causais na determinação de sua conduta no presente (Maturana; Varela, 1997, p. 122).

O histórico do percurso autopoiético leva a modificações estruturais cognitivas no agir. No entanto, na conduta do ser autopoiético essas transformações são percebidas apenas no domínio do observador.

Segundo Maturana (2001a, p. 123), “o conhecimento é uma apreciação de um observador sobre a conduta do outro”. Dessa forma, percebe-se que o conhecimento é adquirido na interação com os outros da mesma espécie. Também se constata que o conhecimento tem ligação direta com a realização de condutas consideradas adequadas ao domínio existencial de convivência. Desse modo, "se quero que alguém adquira conhecimento num certo espaço, o que tenho que fazer é convidá-lo a viver neste certo domínio; se ele aceita, terá esse conhecimento” (Maturana, 2001a, p. 124). 


\section{O ser humano é um ser eminentemente interativo}

Todo ser humano é um ser de relações intra e interpessoais. A humanidade do ser humano se estabelece na convivência com seres da mesma espécie regida pelas compensações de perturbações que fomentam a reestruturação cognitiva. Diante desse panorama, pode-se pensar o processo educativo como a construção de aprendizagens numa autonomia relacional, onde cada um é um ser legítimo na interação com outros legítimos. As relações intra e interpessoais constituem-se em fenômenos biossociais que se manifestam em pensamentos de dúvidas, de certezas e de hipóteses do indivíduo na vivência de suas perturbações e compensações num domínio existencial.

Para compreender como se conhece, é preciso remeter as experiências do cotidiano a partir de três movimentos ininterruptos: observar, explicar e agir. Com efeito, o ser humano ao fazer parte do mundo se coloca no posto de observador e com a experiência sensível que adquire ao observar se propõe a explicar o mundo tal qual o conhece pela sua ação. A experiência do ser humano no mundo é 'subjetiva no coletivo' e a partir dessa complexa e constante relação entre o ser humano e o domínio existencial é que surge o conhecimento.

Os autores do conceito autopoiese afirmam que o fenômeno do conhecimento deriva da nossa experiência cognitiva e que essa se origina do processo autopoiético de compensação de perturbações. Para compreensão da fenomenologia do conhecer, Maturana e Varela se reportam aos conceitos de Organização, Estrutura, Acoplamento Estrutural, Clausura Operacional e Ontogenia que são as bases para a compreensão do processo autopoiético como caminho da evolução dos seres humanos.

De acordo com Maturana e Varela (2001b), quando se busca entender a organização do ser humano fala-se das relações internas de seus componentes. E quando se quer entender a estrutura do ser humano fala-se da configuração concreta de uma unidade autopoiética que interage com o meio. Contudo, para que haja um melhor entendimento das vivências autopoiéticas dos seres humanos é necessário o esclarecimento dos demais conceitos: acoplamento estrutural, clausura operacional e ontogenia. Conforme Maturana e Varela (2003), as definições são as seguintes:

a) Acoplamento Estrutural: conexão entre o ser autopoiético e o domínio existencial. É o conjunto de mudanças que o meio possibilita na estrutura de um determinado organismo e o organismo no meio numa relação sempre recursiva. O ser humano quando influenciado pelo meio, muda e mudado responde provocando alterações no meio que o influenciou;

b) Clausura Operacional: qualquer mudança ocasionada pelo acoplamento estrutural será gerada sempre a partir de modificações estruturais cognitivas no ser humano. As modificações sempre são determinadas pelo interior do organismo vivo e não pelo meio que se relaciona com o mesmo;

c) Ontogenia: história das modificações estruturais cognitivas pelas quais passa um ser autopoiético sem que perca sua organização, promovendo a conservação e a evolução. É o percurso autopoiético que se desenvolve pelas sucessivas compensações das perturbações.

Contudo, esse caminho conceitual da fenomenologia biossocial do ser humano autopoiético não deve ser visto como algo previsível, pois a evolução do ser humano não é previsível, já que não se pode afirmar com total certeza o estágio subsequente na manutenção e ou evolução de um ser autopoiético, pois as alterações estruturais são determinadas a partir do interior de cada ser. 
Dentro dessa dinâmica existencial entre ser humano e o meio em que vive e conhece, a partir da autopoiese, está uma das maiores riquezas do ser humano: a cognição. Em outras palavras, a capacidade imensurável que o ser humano possui de conhecer pela e na linguagem. Para Maturana e Varela (2001b, p. 31) "tal riqueza é tão complexa que sua totalidade é vista como um valor transcendental”.

É importante ter presente que a apresentação de dados, neste trabalho, mostrará alcances e limitações das interações dos tutores de sede ${ }^{4}$ do curso PEAD com os acadêmicos a partir das autonarrativas do portfólio de aprendizagens, considerando que a problematização das autonarrativas de aprendizagens é, de modo geral, atribuição dos tutores de sede.

\section{O portfólio de aprendizagens do curso PEAD}

O Projeto Pedagógico do Curso de Licenciatura em Pedagogia na modalidade a distância (PEAD) salienta que todos os acadêmicos terão atenção constante e individualizada, no sentido de buscar alternativas para resolver dúvidas e problemas inerentes ao uso de recursos diferenciados em um processo de aprendizagem a distância. Como o curso se realiza a distância, as interações serão efetivadas, predominantemente, via ambiente virtual, através de correio eletrônico, fóruns, chat e, de modo especial, de um instrumento de uso individual para a produção de autonarrativas das experiências de aprendizagens durante a maior parte do curso: $3^{\circ}$ ao $8^{\circ}$ semestre. ${ }^{5}$ Esse instrumento denominado de portfólio de aprendizagens constitui-se num suporte telemático no processo avaliativo dos acadêmicos do curso PEAD. A partir desse instrumento online é possível delinear o percurso da construção de aprendizagens dos acadêmicos.

No projeto pedagógico do PEAD a intervenção através da interação é o paradigma para a realização pedagógica. As intervenções da equipe pedagógica, especialmente, dos tutores de sede têm a intenção de problematizar as autonarrativas de aprendizagens dos acadêmicos, através de críticas construtivas ${ }^{6}$ sobre a coerência e a consistência das mesmas. O portfólio de aprendizagens é uma ferramenta tecnológica, alocada no espaço virtual, de armazenamento e processamento de hipertextos e de livre acesso. É um espaço virtual dinâmico onde os acadêmicos postam autonarrativas que relatam o processo da construção das próprias aprendizagens. Dentre as opções dos instrumentos virtuais de interação no curso PEAD, o portfólio de aprendizagens foi o instrumento mais constante na identificação do processo de autoavaliação dos estudantes.

O conceito de portfólio educacional busca refletir a fusão entre processo e produto. É um artefato que mostra as realizações em processo. De um modo geral, o portfólio educacional pode ser visto como um memorial, um registro qualificado [...] o portfólio educacional deve ser uma pasta de exemplo das proposições, das realizações e do investimento na formação, evidenciando os pontos fortes da prática pedagógica e o enfrentamento das limitações (Carvalho; Porto, 2005, p. 13).

No PEAD, o portfólio de aprendizagem é o espaço virtual de registro semanal das aprendizagens de cada acadêmico. O estudante é convidado a fazer os registros tendo presente dois parâmetros: argumento e evidência. Se o acadêmico diz que desenvolveu uma atividade nas aulas com os seus alunos, ele deve narrar o fato, fazer a sua análise dos resultados e expor a sua autoavaliação no confronto com os referenciais teóricos e metodológicos que estudou no curso. Tais postagens são palavras de autoria, 
geradoras de reflexão sobre a própria aprendizagem. Esse fator torna as autonarrativas de cada acadêmico a descrição consciente do fenômeno da própria aprendizagem no contexto do domínio existencial de cada postagem.

Para sustentar esse processo participativo os portfólios de aprendizagens deverão oferecer facilidades para a apresentação das evidências ou testemunhos da aprendizagem na sua dimensão processual, desde as perturbações que desequilibram as certezas do sujeito, até a criação de novas formas de pensar, decorrentes da construção de novos instrumentos cognitivos (Nevado et al., 2006, p. 35).

O portfólio de aprendizagens é um espaço individual de avaliação, mas também coletivo, já que colegas, professores e tutores têm acesso às autonarrativas postadas e podem fazer comentários que possibilitaram perturbações que geram compensações. Entretanto, diante do universo dos agentes interativos, a predominância de interações se estabeleceu entre acadêmicos e tutores de sede. Enfim, o portfólio é uma ferramenta virtual que proporciona ao acadêmico revelar conscientemente o processo de suas aprendizagens e complexificar as limitações, na medida em que forem reveladas as contradições e as inconsistências das autonarrativas.

Na busca da compreensão e aprofundamento dos significados das autonarrativas dos acadêmicos, a pesquisa busca saber o que o curso representou para os acadêmicos, como foi a sistemática de postagens no portfólio de aprendizagens e como a experiência das autonarrativas de aprendizagens auxiliou na evolução da estrutura cognitiva dos acadêmicos. Essas questões são fundamentais para constituir a questão da pesquisa: Como se configura a construção de aprendizagens de acadêmicos no curso de Pedagogia a distância da UFRGS a partir das autonarrativas no portfólio de aprendizagens? Da mesma forma, as questões precedentes corroboram para a definição dos objetivos da investigação:

a) Identificar as perturbações na trajetória das autonarrativas de aprendizagens;

b) Reconhecer as compensações das perturbações ao longo das autonarrativas de aprendizagens;

c) Configurar o histórico da conexão das perturbações-compensações ao longo do processo de construção de aprendizagens.

Ciente da questão e dos objetivos da pesquisa propõe-se um procedimento metodológico condizente com o conceito de autopoiese para dar resposta à questão e alcançar os objetivos. O procedimento metodológico escolhido "redução fenomenológica" dialoga com o conceito de autopoiese a partir da análise qualitativa dos fenômenos vivenciados e autonarrados pelos acadêmicos do curso PEAD.

\section{A redução fenomenológica como procedimento metodológico: análise ideográfica e nomotética das autonarrativas de aprendizagens}

A investigação das autonarrativas de aprendizagens individuais dos acadêmicos encontra respaldo metodológico para ser executada através dos procedimentos de pesquisa qualitativa, pois está relacionada "à capacidade de possibilitar a compreensão do significado e a descrição densa dos fenômenos estudados em seu contexto e não a sua expressividade numérica.” (Goldenberg, 1997, p. 50).

A opção da abordagem qualitativa está relacionada diretamente com a pesquisa fenomenológica, pois trabalha com o real vivido e não com uma verdade teórica ou ideológica imposta. 
A pesquisa fenomenológica fundamenta procedimentos rigorosos, mostrando de que maneira tomar educação como fenômeno e chegar aos seus invariantes para que as interpretações possam ser construídas, esclarecendo o investigado e abrindo possibilidades de intervenção no campo da política educacional e da prática pedagógica. A fenomenologia se mostra apropriada à educação, pois ela não traz consigo a imposição de uma verdade teórica ou ideológica preestabelecida, mas trabalha com o real vivido, buscando a compreensão disso que somos e que fazemos (Bicudo, 1999, p.13).

Da mesma forma que a fenomenologia, como caminho metodológico, busca a explicação do fenômeno vivido e não teorizado, os operadores autopoiéticos: perturbação e compensação buscam operacionalizar a análise do fenômeno da aprendizagem vivido pelos acadêmicos como realidade observada num determinado contexto e não pré-estabelecida por teorizações. Para Maturana (1998, p. 193), “o que o observador distingue é o fenômeno. O que a gente explica como científico é o fenômeno que é a realidade no domínio em que se estabelece”.

O intuito da pesquisa fenomenológica é ir diretamente à experiência vivida. Aquela experiência que perturba que causa inquietação, que tira o ser humano do estado de conforto, ou seja, que vive a sistemática autopoiética da configuração do conhecimento. A investigação fenomenológica trabalha com o fenômeno em si. A compreensão do fenômeno é estruturada pela análise rigorosa dos dados e pela devida interpretação. Martins e Bicudo (2006) indica que essa análise rigorosa dos dados se estabelece através de reduções sucessivas efetuadas em dois momentos distintos na investigação: análise ideográfica e análise nomotética.

\section{Análise Ideográfica das Autonarrativas}

Ao ler, reler e refletir sobre as autonarrativas dos acadêmicos, no contexto em que foram realizadas, percebe-se organizações temáticas que nortearam as suas produções. Essas temáticas remetem-se ao processo de construção dos resultados e, por isso, na análise ideográfica, foram nomeados "episódios ideográficos” 7 .

As autonarrativas se delineiam seguindo as perturbações que as temáticas proporcionam pelas atividades de estudos e práticas propostas nas interdisciplinas estabelecidas pelo PPC do curso.

A fim de efetivar os princípios de integração e interdisciplinaridade, o currículo do curso está organizado em torno de idéias-fonte que constituem os eixos temáticos que agregam e articulam, em cada semestre, os conhecimentos específicos, teóricos e práticos (Nevado et al., 2006, p. 18).

Na análise ideográfica realiza-se a redução fenomenológica que se apresenta em quatro colunas com funções analíticas diferentes, mas complementares (ver Tabela 01). $\mathrm{Na}$ primeira coluna, as transcrições das autonarrativas são feitas na íntegra por considerar todas as falas fonte complexa e, assim, rica em possibilidades de percepções do viver-conhecer das aprendizagens de cada acadêmico. As autonarrativas transcritas na íntegra nomeiam-se "postagens significativas".

A partir da leitura e releitura da íntegra das autonarrativas do acadêmico, buscam-se relatos (trechos) que se conectam ao episódio ideográfico. Esses trechos posicionam-se na segunda coluna e nomeiam-se "unidades de significados". Diante da constatação das unidades de significados nas postagens significativas do acadêmico expõem-se, na terceira coluna, os “comentários no contexto das postagens” com o 
intuito de compreender além do que as linhas apresentam. Esse esforço compreensivo estabelece-se pelos pressupostos autopoiéticos da perturbação e da compensação, os quais são configuram-se, nesta pesquisa, como operadores de análise fenomenológica.

Na quarta coluna, apresentam-se as “ideias-fonte” das autonarrativas. As ideiasfonte são as condensações das ações percebidas nas autonarrativas. São definidas pelo esforço interpretativo do pesquisador, na busca de estabelecer pontos de conexão entre as ações percebidas e a temática de cada episódio ideográfico ${ }^{8}$. Para o pesquisador, esse processo é um imenso desafio e se justifica em si, como diz Gadamer (1997, p. 19), "toda reprodução é imediatamente interpretação e quer ser correta enquanto tal”. 
Resgatamos através da interdisciplina de Música na escola, as músicas que marcaram nossas vidas, fazendo relações com o texto lido "De quem é a música". Foi uma atividade muito interessante, pois além trazer a tona minhas lembranças, pude ver como essas atividades trouxeram contribuições aos meus alunos ao desenvolver essa técnica com eles.

A música desperta emoções e sentimentos. Como coloca a autora do texto, a música possibilita que a mensagem do compositor da música seja passada e que o conteúdo exposto por ele torne-se "nossa própria palavra".

\section{Autonarrativa do Acadêmico PM}

Quando recebemos a proposta da Professora Claúdia da interdisciplina "Literatura infanto Juvenil e aprendizagem B", nosso grupo reuniu-se para decidirmos o que iríamos apresentar.

Nossa colega Cátia trouxe como sugestão o trabalho realizado com muito sucesso em sua escola, onde foi e está sendo realizado por várias professoras em séries diferenciadas contação de história "O gato pirado". Logo que ela iniciou exploração já nos apaixonamos pela história então foi unânime escolha.

Esse trabalho ainda esta sendo realizado, pois é um trabalho que requer participação dos alunos e pais, uma vez que uma das propostas depois de ser contada a história é que cada aluno leve para casa o gato pirado e a partir disso os alunos deverão cuidar desse gato como se ele fosse real e deverão escrever no diário como foi essa visita. Além dessa atividade os alunos poderão criar outro animal pirado, representá-lo através de desenho e escrever uma história para esse animal. Também podemos explorar com os alunos outras informações sobre as diferenças entre os animais, essa atividade poderá ser registrad no caderno do aluno ou através de painéis, álbuns..., ficando critério do professor e conforme a faixa etária dos alunos.

Essa contação de história é muito rica e produtiva, os alunos sentem prazer tanto no momento de ouvir a história, como no momento de interagir com a contacão. São momentos assim que nossos alunos necessitam e os tornam leitores.
Música na escola, as músicas que marcaram nossas vidas, fazendo relações com o texto ido "De quem é a música".

$1.2[\ldots]$ pude ver como essa atividade trouxe contribuições aos meus alunos ao desenvolver essa técnica com eles.

6.1 Nossa colega Cátia trouxe como sugestão 0 trabaho realizado com míto sucesso em sua escola, onde foi e está sendo realizado por várias professoras em série diferenciadas a contação de história "O gato pirado”. Logo que ela iniciou a exploração já nos apaixonamos pela história então foi unânime a escolha.

6.2 Além dessa atividade os alunos poderão criar outro animal pirado, represento través de desenho e escrever uma história para esse animal.

6.3 Essa contação de história é muito rica e produtiva, os alunos sentem prazer tanto no momento de ouvir a história, como no momento de interagir com a contação. São momentos assim que nossos alunos necessitam e os tornam leitores. texto lido trouxe à tona as lembranças das músicas marcantes na infância, na adolescência e na juventude do acadêmico perturbação)

$1.2 \mathrm{O}$ uso da música nas atividades escolares é um recurso didático que contribuiu no desenvolvimento escolar dos alunos (compensação).

6.1 Diz respeito à necessidade da escolha de uma atividade educacional de leitura e escrita que foi realizada rapidamente e com grande expectativa de sucesso. Pela necessidade da realização da escolha em grupo há (perturbação) e pela unanimidade na escolha da atividade há (compensação).

6.2 Refere-se a capacidade de criatividade do acadêmico enquanto professora (compensação).

6.3 A acadêmica atribui valor a prática pedagógica da contação de história associada a prática da leitura como significativa à aprendizagem dos alunos (compensação).
1.2 Ressignificação da prática docente.

6.1 Autonomia nas escolhas

6.2 Ressignificação da prática docente

6.3 Ressignificação da prática docente; Promoção 
Análise Nomotética das Autonarrativas

Após a análise ideográfica, descrita na Tabela 01, novas articulações são efetuadas na busca da identificação estrutural do fenômeno, ou seja, identificar o que continua sendo observado após a redução fenomenológica. Esse novo esforço metodológico denomina-se análise nomotética ${ }^{9}$.

Desta maneira, parte-se das ideias-fonte, definidas na análise ideográfica, e segue-se buscando a essência do fenômeno a partir de novas condensações de significados no confronto e na articulação das ideias-fonte. Em outras palavras, o pesquisador estabelece, a partir das suas percepções sobre as experiências autonarradas que geraram as ideias-fonte, grandes áreas de generalização do fenômeno. Essas grandes áreas são denominadas, dentro do viés autopoiético, marcadores complexos, isto é, "referências de uma conceituação teórico-filosófica que podem se transformar em padrões que conectam, na medida em que são incorporados recursivamente num processo" (Pellanda, 2003, p. 1377). Nessa pesquisa, os marcadores complexos do acadêmico ZS foram: reflexão conceitual e prática pedagógica. Já para o acadêmico PM foram: reflexão conceitual, prática pedagógica e intervenção social. ${ }^{10}$

\section{Interpretando o processo de construção de aprendizagens pelo viés autopoiético da plasticidade: perturbação e compensação como operadores de análise}

O movimento efetuado durante a análise ideográfica e nomotética desvelou articulações que construíram redes de autonarrativas em convergências através de padrões que conectam o modo de ser-agir dos acadêmicos. A rede de autonarrativas de cada sujeito configura o percurso autopoiético da construção de aprendizagens no domínio existencial do curso de Licenciatura em Pedagogia a distância da UFRGS.

As perturbações e as compensações (operadores de análise) podem se estabelecer de diversas formas dentro do percurso autopoiético de cada sujeito. Pelo princípio da evolução, segundo Maturana e Varela (1997), toda perturbação será compensada, entretanto, não é possível perceber o momento exato da compensação de cada perturbação. Sendo assim, elas podem ocorrem, segundo a interpretação do observador, de imediato, na sequência ou após outra perturbação.

Antes de interpretar as diversas formas de relação entre os operadores de análise: perturbações e compensações presentes na plasticidade dos acadêmicos é importante visualizar o fluxo delas. ${ }^{11}$ Para compreender as conexões entre perturbações e compensações dentro da sistemática do processo autopoiético apresenta-se ilustrações da plasticidade autopoiética dos percursos dos acadêmicos investigados. 
A seguir, a figura 01 apresenta a plasticidade autopoiética do acadêmico ZS.

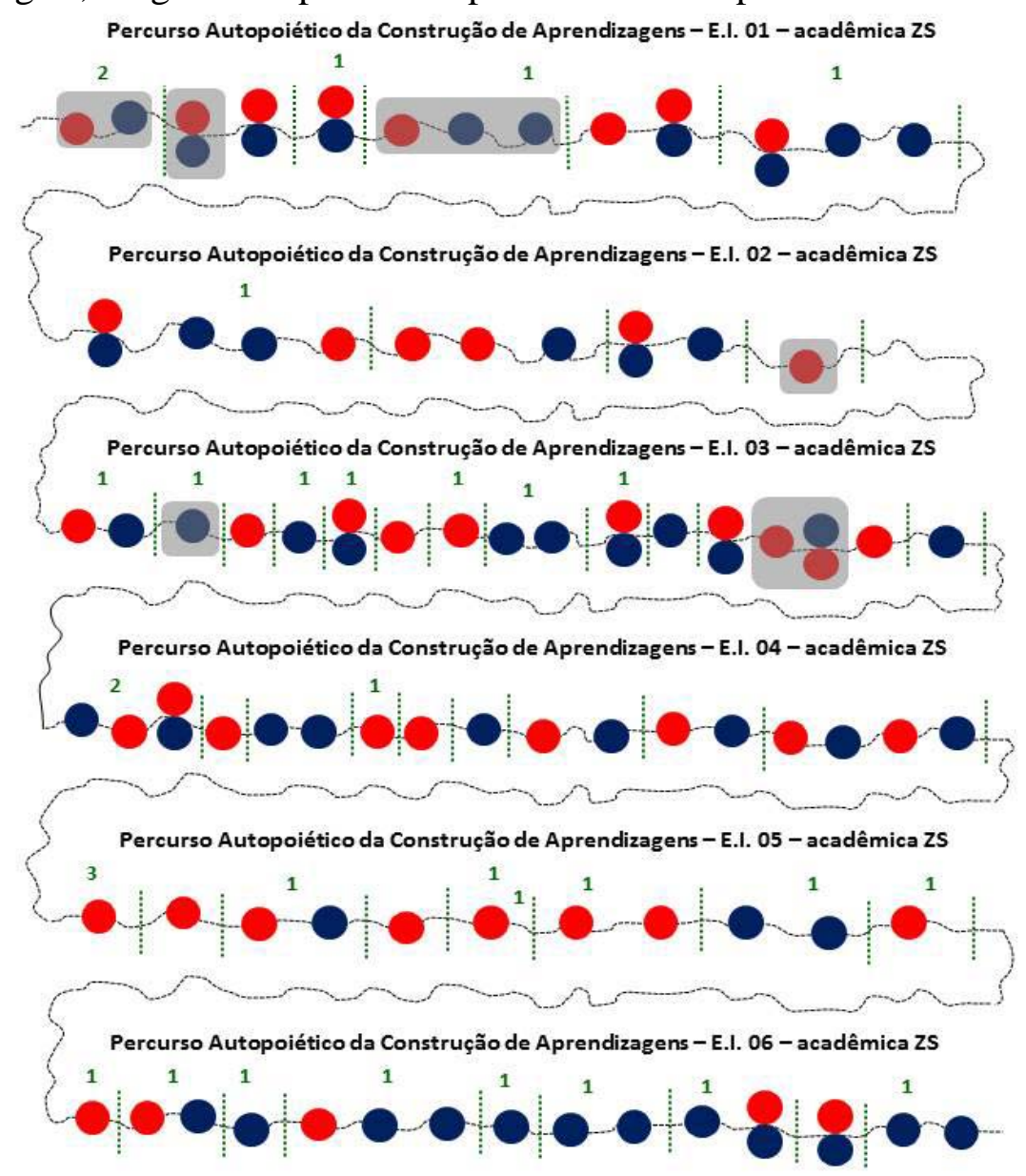

Perturbação Compensação № Intervenção Humana

Figura 01 - Percurso autopoiético da construção de aprendizagens do acadêmico ZS Nota: E.I. = Episódio Ideográfico

Fonte: Lorençatto (2013)

No percurso ilustrado com círculos vermelhos representando as perturbações, com azuis as compensações, com números verdes a intensidade das intervenções dos tutores de sede e com traços pontilhados verdes o espaço entre uma autonarrativa e outra é possível observar a plasticidade autopoiética pela configuração das diversas formas de conexão entre perturbação e compensação.

Dentre elas, apresentam-se: I) perturbação com aparente ${ }^{12}$ compensação posterior. A ilustração se dá pelo círculo vermelho seguido do azul na mesma autonarrativa; II) perturbação com aparente compensação imediata ${ }^{13}$ A ilustração se dá pelo círculo vermelho sobre o azul no mesmo trecho significativo; III) compensação com aparente perturbação imediata. A ilustração é o círculo azul sobre o vermelho; IV) perturbações sem imediata ou posterior compensação. A ilustração se dá pelo círculo vermelho sem conexão anterior ou posterior com círculo azul; V) compensação sem anterior perturbação. A ilustração se dá pelo círculo azul sem conexão anterior com círculo vermelho; VI) perturbação com aparentes compensações posteriores ou pode ser interpretado também como recompensação de compensação 
anterior. A ilustração se dá pelo círculo vermelho com ou sem o círculo azul abaixo e círculos azuis na mesma autonarrativa. Diante de todas essas variações no percurso, a forma predominante de conexão é perturbação com aparente compensação posterior.

A seguir, a figura 02 apresenta a plasticidade autopoiética do acadêmico PM.

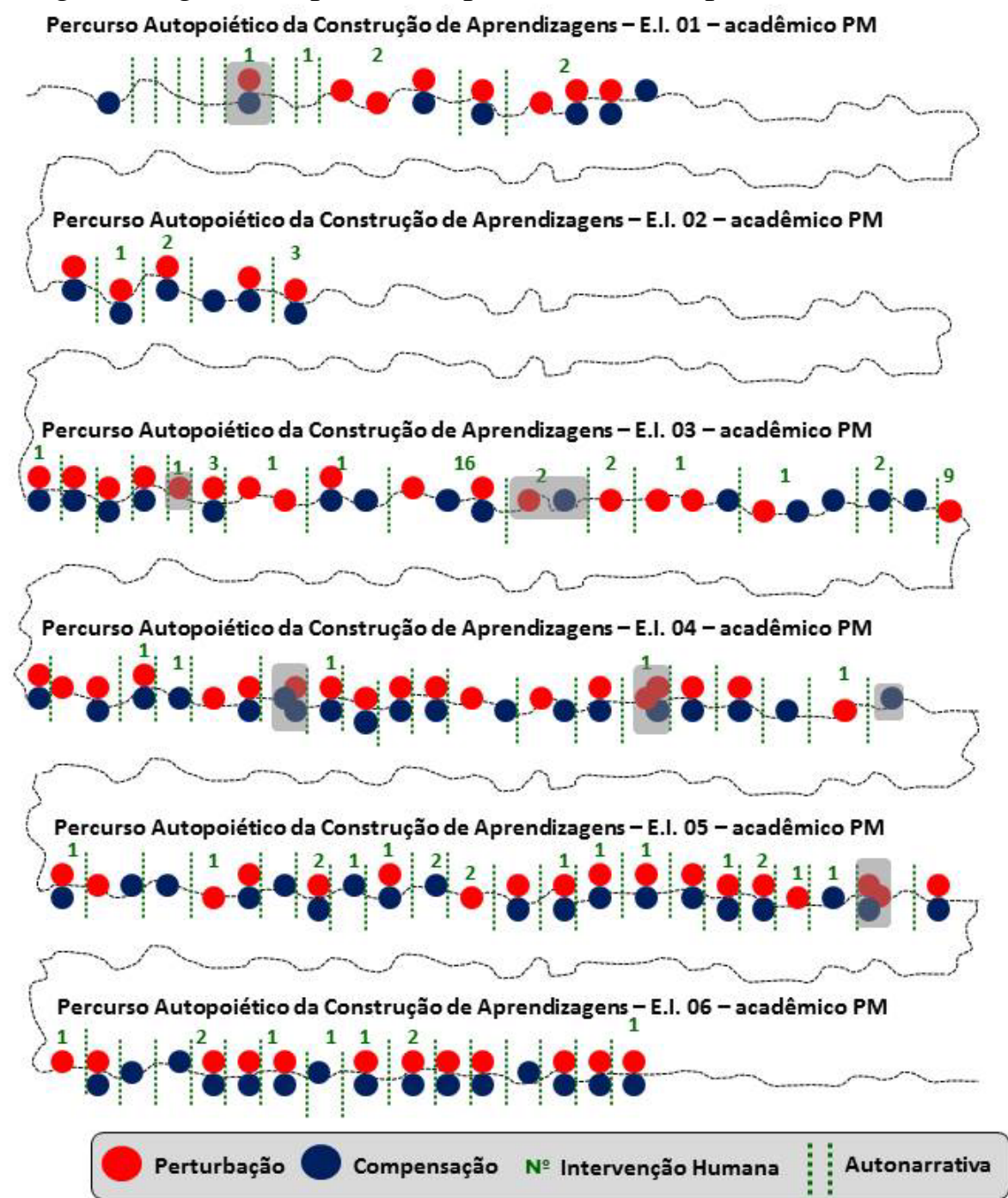

Figura 02 - Percurso autopoiético da construção de aprendizagens do acadêmico PM Nota: E.I. = Episódio Ideográfico

Fonte: Lorençatto (2013)

Seguindo os mesmos indicadores apresentados na análise da Figura 01 é possível observar a plasticidade autopoiética da Figura 02 pela configuração das diversas formas de conexão entre perturbação e compensação.

Dentre elas, apresentam-se: I) perturbação com aparente compensação imediata. A ilustração se dá pelo círculo vermelho sobre o azul no mesmo trecho significativo; II) perturbações sem imediata ou posterior compensação. A ilustração se dá pelo círculo vermelho sem conexão anterior ou posterior com círculo azul; III) compensação sem anterior perturbação. A ilustração se dá pelo círculo azul sem conexão anterior com círculo vermelho; IV) perturbação com aparente compensação posterior. A ilustração se dá pelo círculo vermelho seguido do azul numa mesma autonarrativa; V) compensação seguida de perturbação com aparente nova compensação imediata. A ilustração é o círculo azul ligado a um vermelho acima de outro azul na mesma autonarrativa; VI) 
Semelhante a essa forma há outra: perturbação seguida de outra perturbação com aparente compensação imediata. A ilustração é a círculo vermelho ligado a outro círculo vermelho acima de um azul; VII) perturbação com aparente compensação que gera uma nova perturbação ligada a anterior na mesma autonarrativa. A ilustração é o círculo vermelho sobre o azul ligados a outro vermelho. Diante de todas estas variações no percurso, a forma predominante de conexão é perturbação com aparente compensação imediata.

Todas essas formas de conexão, em ambas as figuras 01 e 02, configuram a plasticidade do percurso autopoiético dos acadêmicos. A plasticidade, nos termos da Biologia da Cognição, é o conjunto de derivações ontogênicas do processo autopoiético. Para Maturana (1998, p. 40) “o que o observador vê em cada instante como conduta é sempre expressão do presente estrutural da unidade do organismo e tal presente estrutural é sempre o resultado de uma derivação estrutural ontogênica”.

Tais derivações ontogênicas configuram a evolução estrutural cognitiva do sujeito a partir da construção de aprendizagens na vivência de um fenômeno. Sendo assim, cada vez que uma perturbação é compensada há evolução da condição humana do acadêmico. A evolução se caracteriza pela manutenção e modificação da estrutura cognitiva do acadêmico. A estrutura cognitiva é a capacidade que o ser humano tem de aprender e está ligada diretamente com as linguagens como expressões vivas de manifestações da construção das aprendizagens no processo autopoiético.

As investigações acerca do processo autopoiético de "construção de aprendizagens", vivenciados pelos acadêmicos investigados, demonstram que os universos do curso PEAD e da escola de atuação profissional dos acadêmicos constituíram-se em domínios existenciais ao promoverem diversas perturbações através das interações dos acadêmicos com outros sujeitos, tais como: professores, tutores e colegas do curso, professores colegas de trabalho e alunos, além das intervenções dos meio onde esses se constituem unidades autopoiéticas concretas.

Durante a configuração do percurso autopoiético sequencial da construção de aprendizagens dos acadêmicos investigados, foram se desenhando, as diversas formas de conexão entre perturbações e compensações, as quais evidenciam a plasticidade autopoiética de cada sujeito.

\section{Conclusão}

A Educação a Distância online é uma modalidade com características especificas de ensino-aprendizagem e de avaliação. Através dela se busca ampliar o acesso ao conhecimento, desde que a produção de conhecimento científico seja oriunda da reflexão sobre o conteúdo que o diálogo proporciona e não apenas o derramamento de informações ou a transferência dos modos da modalidade presencial na estrutura do ambiente virtual de aprendizagem.

Os pressupostos autopoiéticos da perturbação e da compensação nos processos de construção de aprendizagens são importantes nos cursos EAD online que priorizam a autoavaliação como caminho para a produção do conhecimento. Esta visão deve ser levada em consideração no planejamento e desenvolvimento de componentes curriculares e ou cursos a distância online.

A partir da aplicação da metodologia de redução fenomenológica das autonarrativas dos portfólios de aprendizagens foi possível a releitura autopoiética do percurso da construção de aprendizagens dos acadêmicos ZS e PM. Seguindo a complexa sistemática autopoiética, puderam-se identificar perturbações na trajetória das 
autonarrativas, assim como reconhecer compensações dessas perturbações e também configurar o percurso das conexões entre os pressupostos autopoiéticos.

Essas indicações sobre o percurso autopoiético da construção de aprendizagens dos acadêmicos se consolidam diante do viés autopoiéticos da plasticidade. A partir da interpretação da plasticidade autopoiética da construção de aprendizagens dos acadêmicos ZS e PM do curso de Pedagogia a distância da UFRGS é possível apresentar alguns elementos conclusivos da pesquisa. São eles: a) quanto mais críticoconstrutivas são as intervenções dos tutores de sede, mais frequentes é a geração de perturbações e a realização de compensações que alteram a estrutura cognitiva dos sujeitos; b) quanto mais constantes são as intervenções crítico-construtivas dos tutores de sede, mais regular é a presença de perturbação com aparente compensação 'imediata' as quais potencializam a alteração da estrutura cognitiva dos estudantes e c) quanto menos constantes são as intervenções dos tutores de sede, mais regular é a presença de perturbação sem aparente compensação posterior e de compensação sem aparente perturbação anterior o que, no percurso autopoiético, pode-se tratar como um 'ponto sem nó’ o qual não contribui para a restruturação cognitiva dos acadêmicos.

Esses elementos conclusivos do processo autopoiético aplicados nessa pesquisa, observados no contexto atual de expansão da Educação a Distância no país, principalmente no que tange os cursos de formação docente, são indicativos-chave para a qualificação dos processos de intervenção pedagógica na ressignificação da construção de aprendizagens de acadêmicos da modalidade de educação a distância online.

É importante ressaltar que as dinâmicas pedagógicas autoavaliativas, mediadas por ferramentas virtuais, despertam em quem está em formação a reflexão sobre o entendimento de aprendizagem e lançam novos desafios aos processos comunicativos autoavaliativos, com impactos ainda não muito explorados quanto à reestruturação cognitiva dos sujeitos envolvidos.

\footnotetext{
${ }^{1}$ Entende-se por autonarrativas “incompletas” aqueles que não cumpriram com a função do portfólio que é a narração de aprendizagens através de argumentos e evidências das experiências.

${ }^{2} \mathrm{O}$ portfólio de aprendizagens configura-se num domínio existencial do curso PEAD.

3 As inquietações geram as perturbações que configuram todas as ações que promovem mudanças na estrutura dos seres humanos.

${ }^{4}$ Os tutores de sede são aqueles que dão suporte a distâncias às atividades do curso através da plataforma digital.

${ }^{5}$ Nos $1^{\mathrm{a}}$ e $2^{\mathrm{a}}$ semestres foram realizados Memorias e no $9^{\circ}$ semestre estão autonarradas as aprendizagens dos semestres anteriores relacionadas ao Trabalho de Conclusão do Curso (TCC).

${ }^{6}$ Entende-se por críticas construtivas as intervenções que provocam a metacognição dos acadêmicos sobre suas autonarrativas de aprendizagens. Desta forma, não se considera como críticas construtivas intervenções do tipo: “OK”, “Parabéns pela postagem” ou "Boa postagem”.

${ }^{7} \mathrm{O}$ termo ideográfico refere-se à condensação de ideias individuais apresentadas em textos descritivos numa ideia-fonte (Bicudo, 2000).

${ }^{8}$ A análise ideográfica da redução fenomenológica gerou 25 ideias-fonte a partir das autonarrativas do acadêmico ZS e 44 ideias-fonte a partir das autonarrativas do acadêmico PM.

${ }^{9} \mathrm{O}$ termo nomotético deriva de nomos e quer dizer: uso de leis, elaboração de leis (Bicudo, 2000).

${ }^{10}$ Por não ser o foco da pesquisa, a Análise Nomotética das autonarrativas não será aprofundada neste artigo.

${ }^{11} \mathrm{O}$ fluxo de (perturbações) e (compensações) está identificado na $3^{\mathrm{a}}$ coluna do quadro da redução fenomenológica (Tabela 01) onde constam os comentários do pesquisador sobre a identificação concreta de situações de perturbações e de compensações como operadores de análise.

${ }^{12}$ Usa-se o termo “aparente” porque não é possível identificar com exatidão que compensação é de qual perturbação.
} 


\footnotetext{
${ }^{13}$ Entende-se o termo "imediata” no sentido da compensação estar identificada na mesma autonarrativa e, principalmente, por estar no mesmo excerto (unidade de significado).
}

\section{Referências Bibliográficas}

BICUDO, M. A. V. A contribuição da Fenomenologia à Educação. In: BICUDO. M. A. V.; CAPPELLETTI, I. F. (Orgs). Fenomenologia: uma visão abrangente da educação. São Paulo: 1999.

. Fenomenologia: confrontos e avanços. São Paulo: Cortez Editora, 2000.

CARVALHO, M. J. S; PORTO, L. S. Portfólio Educacional: proposta alternativa de avaliação: Guia Didático. Porto Alegre: UFRGS, 2005.

GOLDENBERG, M. A arte de Pesquisar: como fazer pesquisa qualitativa em Ciências Sociais. Rio de Janeiro: Record, 1997.

LORENÇATTO, Mauro. O processo autopoiético e a construção de aprendizagens: conexões entre perturbações e compensações. Um estudo fenomenológico de portfólios de dois acadêmicos do curso de pedagogia a distância da UFRGS. Tese (Doutorado em Educação - Tese defendida em 31/7/2013. Aguardando aprovação final da banca). Programa de Pós-Graduação em Educação. Universidade Federal do Rio Grande do Sul, 2013.

MARTINS, J.; BICUDO, M. A. V. Estudos sobre Existencialismo, Fenomenologia e Educação. 2. ed. São Paulo: Centauro: 2006.

MATURANA, Humberto. De máquinas e seres vivos: autopoiese - a organização do vivo. Porto Alegre: Artes Médicas, 1997.

Da Biologia à Psicologia. 3. ed. Porto Alegre: Artes Médicas, 1998.

Cognição, Ciência e Vida Cotidiana. Belo Horizonte: Editora UFMG, 2001a.

Autopoiesi e Cognizione: la realizzazione del vivente. 3.ed. Venezia (IT):

Marsilio: 2001b.

MATURANA, Humberto; VARELA, Francisco. A Árvore do Conhecimento: as bases biológicas da compreensão humana. 3.ed. São Paulo: Patas Athena, 2003.

NEVADO, R. A; CARVALHO, M. J. S.; BORDAS, M. C. Licenciatura em Pedagogia a distância: anos iniciais do ensino fundamental. Guia do Aluno. Porto Alegre: PEAD/UFRGS, 2006.

OLIVEIRA, Clara Costa. A educação como processo auto-organizativo. Lisboa: Instituto Piaget, 1999. 
PELLANDA, Nize Maria Campos. Conversações: modelo cibernético da constituição do conhecimento/realidade. Revista Educ. Soc., Campinas, vol.24, n.85, p. 1377-1388, dez. 2003.

Maturana \& Educação. Belo Horizonte: Autêntica, 2009.

SANTAELLA, Lúcia. Matrizes da linguagem e pensamento: sonora, visual e verbal. 3.e. São Paulo: Iluminuras, 2005. 